\title{
USOS E FUNÇÕES DOS PROVÉRBIOS INSERIDOS NA POESIA POPULAR PORTUGUESA E BRASILEIRA
}

Anamarija Marinović (Universidade de Lisboa)

Este trabalho debruça-se sobre o uso e funções dos provérbios nas cantigas populares do corpus português $e$ brasileiro. Partir-se-á de alguns conceitos teóricos, visando ao melhor entendimento dos usos dos provérbios na poesia popular portuguesa e brasileira e de sua função educadora e moralizadora.

POESIA POPULAR PORTUGUESA E BRASILEIRA, FOLCLORE, PROVÉRBIOS, TEMÁTICA, USOS E FUNÇÕES DO MATERIAL PROVERBIAL NAS CANTIGAS, VARIANTES PORTUGUESAS E BRASILEIRAS DAS CANTIGAS E PROVÉRBIOS.

MARINOVIĆ, Anamarija. Usos e funções dos provérbios inseridos na poesia popular portuguesa e brasileira. Textos escolhidos de cultura e arte populares, Rio de Janeiro, v.9, n.2, p. 7-19, nov. 2012. 


\section{THE USE AND FUNCTION OF PROVERBS IN BRAZILIAN AND PORTUGUESE POPULAR POETRY}

Anamarija Marinović (University of Lisbon)

This paper focuses on the use and functions of proverbs in popular songs in the Brazilian and Portuguese corpus. It is based on some theoretical concepts, aiming at the better understanding of the uses of proverbs in Portuguese and Brazilian popular poetry and its educational and moralizing roles.

USAGE AND FUNCTIONS OF PROVERBIAL MATERIAL IN THE SONGS, VARIATIONS IN PORTUGUESE AND BRAZILIAN SONGS AND PROVERBS, PORTUGUESE AND BRAZILIAN POPULAR POETRY, FOLKLORE, PROVERBS, THEME.

MARINOVIĆ, Anamarija. Usos e funções dos provérbios inseridos na poesia popular portuguesa e brasileira. Textos escolhidos de cultura e arte populares, Rio de Janeiro, v.9, n.2, p. 7-19, nov. 2012. 


\section{INTRODUÇÃO}

Uma das finalidades deste trabalho será comparar a poesia popular portuguesa e brasileira, tendo em conta um aspecto particular: o uso e funções dos provérbios inseridos nas cantigas. A temática do cancioneiro foi escolhida porque a pesquisa da poesia popular portuguesa nos conduziu à elaboração da dissertação de doutoramento e a um livro sobre o trabalho de Teófilo Braga na recolha e preservação das cantigas populares, que em breve estará disponível. A literatura popular é área de nosso grande interesse e nesse domínio temos vindo a desenvolver todos os nossos trabalhos de pesquisa. Optamos também por explorar a temática proverbial primeiramente porque tanto nas cantigas portuguesas como nas brasileiras observamos a utilização dos provérbios como versos das cantigas. Em segundo lugar está o fato de os provérbios, por sua estrutura às vezes rimada, facilitarem a memorização e transmissão, nisso se assemelhando à poesia. A última razão de nos debruçarmos sobre o material proverbial inserido na poesia popular é a necessidade de divulgar o trabalho da Associação Internacional de Paremiologia (AIP-IAP) com sede na cidade de Tavira, Portugal, que anualmente organiza colóquios internacionais em que se promove o estudo dos provérbios da perspectiva interdisciplinar.

Para os efeitos deste trabalho partir-se-á das definições da literatura popular e literatura de expressão oral, sendo a segunda denominação mais usada no Brasil e que parece resolver muitas das questões polêmicas que têm sido levantadas em torno das designações desse tipo de literatura nos círculos científicos. Após enquadramento teórico mais abrangente, ver-se-á o lugar dos provérbios e expressões proverbiais no âmbito da literatura popular. Por expressões proverbiais, de acordo com conceito próprio, entendemos aquelas expressões que pela estrutura, forma e conteúdo fazem lembrar os provérbios conhecidos e "canônicos", mas que não aparecem registrados em coletâneas e dicionários de provérbios. Neste trabalho não serão abordadas as expressões idiomáticas, as frases fixas e construções comumente usadas com sentido figurado por um lado porque isso alargaria demasiado nosso corpus e por outro porque consideramos que esse material pertence mais ao domínio da fraseologia.

No que diz respeito às fontes consultadas para a elaboração deste trabalho, mencionaremos apenas algumas: Braga (1914), Leite de Vasconcellos (1890), Sílvio Romero (1893) , Luís da Câmara Cascudo (1984) e outros, porque esses autores se podem considerar entre os mais eminentes especialistas em matéria de folclore e literatura popular portuguesa ou brasileira. 
Abordar-se-á o assunto da existência dos provérbios brasileiros, bem como sua diferenciação dos portugueses. Inseridos no contexto da poesia popular, ver-se-á a posição dos provérbios dentro das cantigas e sua função, como também será estudado que tipo de provérbios é usado nos diferentes gêneros de cantigas. Do ponto de vista formal, estudar-se-ão apenas as quadras e não outras formas métricas e outros gêneros poéticos (romances, xácaras, parlendas, orações etc.), uma vez que a quadra é a forma métrica sem dúvida mais dominante na poesia popular portuguesa e, pelo que temos pesquisado, também é bastante frequente na brasileira. A razão da frequência dessa forma métrica muitas vezes explica-se pela natureza e melodia da língua e, como a língua portuguesa é comum tanto para o espaço cultural português como para o brasileiro, esse seria um dos possíveis fatores que explicaria o uso da quadra na poesia popular portuguesa e brasileira.

Uma vez que a temática mais representada no cancioneiro popular português e brasileiro é a amorosa, ver-se-á que tipo de provérbios se adequa mais ao conteúdo amoroso, sendo o amor um dos segmenntos da vida para o qual a sabedoria popular guarda mais conselhos, chamamentos de atenção e reparos que considera necessários fazer para alertar os apaixonados para os possíveis erros e situações não desejadas.

\section{EM TORNO DOS CONCEITOS LITERATURA POPULAR, LITERATURA DE EXPRESSÃO ORAL E FOLCLORE}

Nesta parte da pesquisa prestar-se-á atenção a questões terminológicas importantes que têm levantado muitas polêmicas entre os especialistas portugueses: literatura oral/tradicional e popular por um lado e literatura de expressão oral, forma mais usada pelos pesquisadores brasileiros, que do ponto de vista prático parece resolver um determinado número de problemas nessa área. A primeira imprecisão que se apresenta do ponto de vista teórico é a aparente contradição no uso do termo "literatura", proveniente da palavra latina littera, que significa "letra" e que imediatamente remete para o registo escrito, não se considerando apropriado para a oralidade em que esse tipo de literatura surgiu e foi transmitido. Para substituir essa palavra, que lhe preceu incorreta, o especialista espanhol em matéria do folclore e cultura popular Ramón Menéndez Pidal, na parte introdutória de seu Romancero Hispánico, propõe a expressão "literatura tradicional", justificando a escolha pelo fato de ela ser transmitida durante muito tempo dos mais velhos para os mais novos, criandose dessa forma uma tradição de transmissão de valores, crenças, costumes e 
normas comportamentais. Essa expressão, contudo, é também considerada imprecisa e inadequada, devido à latitude do significado da palavra "tradição", que se aplica a muitas áreas além da literatura.

O tema ocupou também a atenção de Carlos Nogueira (2004) que estabelece diferença entre a "literatura tradicional oral", que abrange todas as criações populares transmitidas oralmente e "literatura tradicional escrita", que se refere à literatura de cordel, destinada também a públicos vastos, embora se transmitisse através das folhas de cordel.

O problemma que surge com a denominação "literatura popular" é precisamente a ambiguidade do termo "popular". Se se analisar a etimologia dessa palavra, ver-se-á que em sua raiz está o "povo" e que portanto deveria remeter para algo que é criado pelo povo, transmitido por ele e a ele destinado. Os defensores desse nome são alguns dos pesquisadores mais antigos, tais como José Leite de Vasconcellos (1890), Teófilo Braga (1914), Jaime Cortesão (1914), mas também Maria Arminda Zaluar Nunes (1978) e Manuel Viegas Guerreiro (1978). Neste momento surge a necessidade de explicar o uso das expressões "literatura popular" e "cultura popular" no sentido moderno. Bernard Waites (CASCUDO, WAITES et al., 2001) explicando a designação "cultura popular" usada no sentido contemporâneo, refere obras de produção massiva, feitas para captar a atenção de públicos vastos e de diversificado grau de escolarização e de várias faixas etárias. Hoje em dia, quando se usam as designações "literatura" e "cultura popular" geralmente se pensa nos materiais de caráter bastante comercial, que se vendem muito bem e que satisfazem um grande leque de gostos, sendo seu valor estético e os critérios segundo os quais foram criados muitas vezes questionados ou considerados de qualidade duvidosa. A cultura e a literatura populares entendidas no sentido tradicional da palavra foram desvalorizadas até o século XIX, precisamente por razões semelhantes àquelas pelas quais agora é menosprezada a cultura de massas. Só com o Romantismo e o período da criação dos estados nacionais, e a reivindicação da língua e das tradições populares é que esse tipo de literatura começa a ganhar novo valor e importância.

Neste momento parece pertinente remeter um pouco às fontes e vias de transmissão da literatura popular, em que a oralidade sem dúvida tem notável papel. Essa é a razão de alguns pesquisadores optarem pelas designações "literatura de expressão oral" ou "literatura de transmissão oral", o que ajuda em grande medida compreender-se seu surgimento e as vias que foram utilizadas para sua preservação e divulgação numa comunidade. João David de Pinto Correia (1998) no artigo "A literatura popular e as suas 
marcas na produção literária portuguesa do século XX", para evitar o equívoco terminológico presente no sintagma "literatura oral", propõe o neologismo "oratura", não aceito nem pelos teóricos nem pelos historiadores de literatura, nem pelo público leitor, porque parece excessivamente artificial.

No Brasil a terminologia usada quase obrigatoriamente compreende a oralidade. Luís da Câmara Cascudo, um dos pesquisadores mais eminentes dessa matéria em duas de suas obras aplica a expressão "literatura oral", explicando que esse sintagma foi inventado em 1881 limitando-se principalmente aos provérbios, contos, adivinhas, frases feitas, orações e cantos, para mais tarde se alargar para outros gêneros. É interessante constatar que o autor, no contexto da literatura oral, situa as mais diversificadas formas e gêneros, começando pelos provérbios. Parece sintomático que os provérbios encabecem a lista de criações populares porque uma de suas possíveis tentativas de definição abrange a ideia de que eles representam formas concisas em que se expressa a sabedoria do povo transmitida oralmente de geração em geração. Após uma primeira abordagem do conceito do provérbio, parece-nos que é o momento adequado para introduzir a noção de folclore. Hoje em dia essa palavra é bastante abrangente e remete a todo tipo de tradições populares, desde a música, os costumes, os trajes, as crenças, as festas populares etc., mas no século XIX, quando foi inventada, referia-se exclusivamente ao significado básico dos termos ingleses folk lore, traduzidos como "saber" ou "sabedoria do povo", e agora parece mais claro por que os provérbios integram a literatura popular e o folclore de cada povo. Com respeito ao folclore, o pesquisador brasileiro José Carlos Rossato (CASCUDO e ROSSATO, 1987) refere que dedicarse ao folclore não significa apenas "matar saudades" dos "velhos tempos", porque o folclore representa o estudo do homo sapiens em seu quotidiano. É importante salientar que esse autor propositalmente não usou o vocábulo "homem" e optou pelo termo latino, porque o adjetivo sapiens deriva de sapientia que justamente significa "sabedoria." Esta parte das reflexões teóricas contribuirá para melhor compreensão dos provérbios que serão abordados com mais atenção a seguir.

\section{PROVÉRBIOS: TENTATIVA DE DEFINIÇÃO E CARACTERÍSTICAS FORMAIS: ESTRUTURA, RIMA E ELEMENTOS GRAMATICAIS IMPORTANTES (TEMPOS E MODOS VERBAIS)}

Nesta parte do trabalho serão estudados os provérbios mais "de perto", tentando referir algumas tentativas de especialistas nessa área para definir 
o provérbio abordando também alguns dos aspectos formais (estruturais e gramaticais) que podem servir de parâmetros para determinar quando uma expressão deve ser considerada provérbio. Em palavras simples podem-se apontar duas características inevitáveis: sua forma relativamente fixa e seu caráter moralizador. A primeira observação que implica a relatividade da forma estável revela que um provérbio, tal como qualquer outro gênero popular é sujeito a alterações, devido à transmissão oral, às diferentes localidades em que é usado, aos vários compiladores que o registaram etc. A parte que envolve o caráter moralizador indica que um provérbio nunca é neutro, encerrando em si algum ensinamento, norma comportamental, conselho, advertência, proibição ou constatação que serve de argumento ou de confirmação de uma verdade. Esse componente é justamente um dos elementos fundamentais pelos quais se há de diferenciar um provérbio de uma expressão popular, um fraseologismo ou expressão idiomática.

Neste trabalho não se prestará atenção aos pormenores terminológicos e diferenças entre os conceitos "provérbio", "ditado", "máxima”, "rifão" e outros afins, por um lado porque essa problemática ainda suscita muitas polêmicas entre os paremiólogos, por outro porque isso ultrapassaria largamente os objetivos deste artigo

Entrando já na temática proverbial do ponto de vista de uma tentativa de definição dos provérbios, Maria Alice Moreira dos Santos (2000), na introdução a um dicionário de provérbios, refere que eles representam a sabedoria de um povo e traduzem a maneira de pensar e os sentimentos das pessoas. No que diz respeito à parte da definição que remete para a forma de pensar, pode chegar-se à conclusão de que os provérbios não só transmitem a experiência e o saber do povo, mas detêm além disso grande carga cultural e são o reflexo da realidade de determinada comunidade. No que diz respeito à transmissão de sentimentos nos provérbios, cabe lembrar que em todas as culturas existem provérbios em que se dão conselhos e em que se chama a atenção para a esfera emocional, sendo, assim, numerosos os que se referem ao amor, à raiva, à tristeza e a outros sentimentos. Definindo o provérbio de forma mais científica, Cláudia Maria Xatara e Thais Marini Succi (2008) informam que se trata de unidade fraseológica e léxica fixa, consagrada pelo povo, e que transmite experiências vividas em comum e expressas de forma sucinta e fácil de memorizar. $O$ fato de essas autoras considerarem o provérbio uma unidade fraseológica salienta a presença de sentidos figurados nos provérbios e a dificuldade de eles se distinguirem corretamente dos fraseologismos, o que aqui não será discutido mais profundamente. Há opiniões de acordo com as quais a 
palavra "provérbio" é derivada do sintagma "verbo aprovado", isto é uma forma de falar que foi aceita e consentida por uma comunidade. O que também chama a atenção é o uso do termo "verbo" e não "palavra", "expressão" ou outro afim, porque do ponto de vista gramatical o verbo indica alguma ação, tal como os provérbios, que quase sempre sugerem maneiras de agir em determinadas situações.

Tendo mencionado algumas das possíveis abordagens do provérbio do ponto de vista teórico, debruçar-nos-emos mais em sua estrutura e na parte gramatical, para avaliar de que forma a estrutura do provérbio está relacionada com seu conteúdo. Em primeiro lugar, do ponto de vista sintático, convém lembrar, cada provérbio é uma frase, que obedece a todos os critérios segundo os quais a frase é reconhecida e nomeada uma construção gramatical que transmite uma ideia. No caso dos provérbios essa construção gramatical pode ter a forma de uma frase simples ou composta, coordenada ou subordinada. Do ponto de vista de tempos verbais, os mais frequentes são o presente e o futuro de indicativo, porque o primeiro indica a certeza de uma ação, uma ação que deve confirmar uma verdade, e o segundo serve para indicar a sequência lógica daquilo que acontecerá ou não se se obedecer ao verbo que na primeira parte do provérbio está no presente de indicativo. O modo verbal mais utilizado nos provérbios e expressões proverbiais é sem dúvida o imperativo, porque através de sua utilização exprimem-se conselhos, sugestões, ordens, pedidos e opiniões que o povo dirige ao público que ouve os ditados e que os transmite. Com certeza podem-se encontrar mais elementos gramaticais nos provérbios, tendo cada um sua função específica; aqui, entretanto, foram abordados apenas os mecanismos mais básicos, visando mostrar que esses tempos e modos verbais influenciam a forma como uma ideia é pronunciada e que eles estão diretamente relacionados com o conteúdo do provérbio. Outra característica importante presente em grande número de provérbios é a rima, também acompanhada de determinado ritmo, podendo a primeira e a segunda parte da expressão ter o mesmo número de sílabas. Esses elementos aproximam o provérbio da poesia, o que facilita sua memorização e transmissão oral, determinando maior frequência de seu uso na linguagem quotidiana. Por esse motivo não é de estranhar que a poesia popular faça uso do material proverbial, o que será analisado a seguir. 


\section{USOS E FUNÇÕES DOS PROVÉRBIOS NA POESIA POPULAR COM EXEMPLOS CONCRETOS DO CANCIONEIRO POPULAR PORTUGUÊS E BRASILEIRO}

Aqui serão observados os usos e funções dos provérbios inseridos nas quadras populares portuguesas e brasileiras, partindo-se da análise da posição do provérbio. Se uma expressão proverbial se encontra no verso inicial da cantiga ou em sua primeira metade, isso significa que os últimos dois versos vão representar um tipo de conclusão do poema a que se chega depois de se ter feito uma espécie de glosa dos provérbios pelos quais começa a cantiga. Os provérbios na posição inicial dentro da quadra introduzem uma ideia que será o eixo do poema e sobre a qual se deve refletir. Às vezes acontece também que os primeiros dois versos da cantiga sejam provérbios de significados aparentemente contraditórios, como mostram estes exemplos (BRAGA, 1914, p. 1; ROMERO,1893, p. 597): "quem canta seu mal espanta / Quem chora seu mal aguenta".

Embora pareça não haver nehuma ligação entre esses dois primeiros versos, o conteúdo das duas cantigas mencionadas reflete a situação de alguém que está triste e gostaria de chorar, mas opta por cantar para disfarçar seus verdadeiros sentimentos, Na coletânea brasileira (ROMERO, 1893, p. 643) aparece mais um exemplo de cantigas com provérbios de sentido oposto: "Quem espera desespera, / Quem espera sempre alcança".

Começa-se pela afirmação de que a ação de esperar não dá o resultado desejado, constatação logo a seguir negada, terminando-se com a conclusão de que a vida na esperança é o maior alívio que uma pessoa pode ter. O fato de numa língua existirem dois provérbios opostos sobre o mesmo fenômeno não significa que necessariamente eles se contradigam, apenas confirma que os seres humanos têm o direito de reagir de formas diferentes a situações parecidas. Desse modo, quando se tem algum problema, tanto é permitido chorar como cantar ou pode acontecer de o ato de esperar pôr à prova a paciência das pessoas, fazendo com que "desesperem" ou que "sempre alcancem" seu objetivo.

A posição média dos provérbios nas cantigas é muito menos frequente, podendo-se, porém, encontrar alguns casos, tal como o demonstra o Cancioneiro Popular Portuguez (BRAGA, 1914, p.16): "quem ama não quer conselho, / Quer tudo o que o amor quer" 
No início da cantiga explica-se uma situação em que os amantes tentam defender seu amor e sua relação das pessoas inoportunas que fazem comentários indevidos; no terceiro verso manifesta-se claramente a vontade de não ouvir os conselhos mal-intencionados; e conclui-se com uma expressão popular, embora não proverbial, que permite aos apaixonados viver todas as situações agradáveis e desagradáveis que o amor proporciona. Na coletânea de cantigas brasileiras que consultamos quase não se encontram exemplos do provérbio "solto" no terceiro verso da cantiga, mas são numerosos os casos em que dois provérbios aparecem na segunda parte da quadra, como conclusão natural das ideias expressas no início. Apenas para ilustrar, seguem-se alguns exemplos ( BRAGA, 1914, p. 54): “quando falares dos outros, / Olha para ti primeiro".

Esse final da cantiga serve como advertência para quem critica a vida alheia sem primeiro se concentrar nos próprios defeitos. No cancioneiro brasileiro (ROMERO, 1893, p. 515) encontra-se um caso interessante de conclusão proverbial: “Quem é mestre também erra, / Quem erra também ensina".

Uma vez que em Teófilo Braga e em outros cancioneiros portugueses que consultamos não se encontram esses provérbios, poder-se-ia pensar que se trata de provérbios meramente brasileios, uma vez que existem no Brasil muitos provérbios usados também em Portugal, quer em sua forma igual ("Quem ama não teme a morte, quem teme não sabe amar") que tanto aparece em Braga como em Romero, ou em suas variantes, sendo na coletânea brasileira apontado (ROMERO, 1893, p. 504): “quem tem zelo tem paixão”, e em Braga (1914) são mencionadas "paixões".

É também comum na poesia popular tanto portuguesa como brasileira a presença de frases que introduzem um provérbio, tais como "já tenho ouvido dizer", "lá diz um verbo antigo" e outras que servem para dar mais credibilidade à afirmação que se expõe na quadra, uma vez que o fato de ter sido ouvido por muitas pessoas e sua antiguidade garantem a sabedoria e a eficácia do conselho que se dá.

Chegou-se a confirmar através da consulta de diferentes páginas da web e da coletânea compilada por Leandro Mota (1987) a presença de provérbios puramente brasileiros, em que se mencionam determinadas plantas e animais específicos do clima e território do Brasil (serpentes, macacos, cajus, abacaxis), bem como palavras típicas da linguagem usada em várias localidades brasileiras; nas cantigas populares brasileiras da antologia que consultamos verificamos, contudo, mais o uso e a existência de provérbios que são comuns na língua 
portuguesa tanto no espaço cultural de Portugal como no brasileiro. Não serão investigadas aqui as eventuais razões para tal escolha do material proverbial nas cantigas brasileiras porque isso ultrapassaria um pouco os objetivos deste trabalho.

Tanto no cancioneiro popular português como no brasileiro são também frequentes as alusões a provérbios e expressões populares que possuem todos os elementos necessários ao enquadramento na categoria provérbios (nomeadamente a estrutura fixa, tempos e modos verbais exigidos, tipo de construções frásicas e o caráter moralizador), mas que não constam nas coletâneas de provérbios "conssagrados", o que é apenas um bom indicador de que a sabedoria popular não é assunto reservado a livros e petrificado, e de que a língua é um organismo vivo que continuamente evolui e cria novas formas proverbiais.

Para ilustrar algumas alusões a provérbios, citaremos um exemplo português e outro brasileiro, de forma a indicar que, embora não diretamente mencionados, os provérbios ecoam através dos versos das cantigas, o que confirma sua presença visível e forte no imaginário das pessoas.

Em Braga (1914, p. 135) pode-se encontrar o verso "quem namora sempre alcança", clara alusão ao provérbio conhecido e aceito nas culturas portuguesa e brasileira "quem espera sempre alcança". Introduzindo o conceito de namoro no âmbito desse provérbio, entende-se que quem está apaixonado às vezes deve esperar pelo momento mais adequado para realizar o desejo de namorar a pessoa que ama. No cancioneiro brasileiro que está sendo consultado (ROMERO, 1893, p. 392) encontram-se os seguintes versos: "Leva-me longe da vista, / Porém do sentido não".

Neles ecoa o provérbio conhecido "quanto mais longe da vista, mais perto do coração", que significa que nem a distância física é capaz de destruir os verdadeiros sentimentos de uma pessoa.

A temática proverbial amorosa é visivelmente dominante tanto no cancioneiro português como no brasileiro, uma vez que as cantigas que falam de amor ocupam o lugar mais importante na poesia popular desses dois países. Dessa forma nos dois cancioneiros é possível encontrar provérbios como: "Quem muito ama muito perdoa", "quem ama nunca se enfada", "quem quer bem nunca quer mal", "quem tem amores tem ciúmes", "mal de amores não tem cura", "quem quer bem não dorme", "amor com amor se paga". A sabedoria popular aborda mais vezes a área do amor precisamente porque nessa matéria as pessos são mais sensíveis e tendem a cometer mais erros, considerandose, portanto, que conselhos e advertências se fazem mais necessários. Às vezes 
acontece também que um provérbio de temática que à primeira vista nada tem a ver com o amor se enquadre bem na cantiga, uma vez que os demais versos são claramente amorosos. É o caso, por exemplo, do provérbio já referido "quem espera sempre alcança". Se não tratam da temática de amores, ciúmes, paixões e todos os demais sentimentos que se relacionam estreitamente com esse afeto, os provérbios abordam uma temática mais geral e referem-se à prudência em determinadas situações da vida, à esperança, à saúde, à verdade e outras "grandes categorias" que fazem parte da vida quotidiana das pessoas. Se a função dos provérbios em geral é a de ensinar, advertir, aconselhar, sua função nas cantigas é também a de divertir e de deleitar, porque, expressandose em versos, facilitam a memorização e ampliam a imagem neles evocada.

\section{CONCLUSÕES}

Depois de abordagem teórica sobre as noções da literatura popular ou de expressõ oral, folclore e provérbio, tentou-se verificar qual é o uso e a utilidadee dos provérbios inseridos nas cantigas populares portuguesas e brasileiras. Na comparação dos dois corpora, foram encontradas várias semelhanças entre a poesia popular desses dois países, sobretudo na forma e posições dos provérbios, tendo o material proverbial no início da cantiga a função de introduzir a "problemática central" que se vai desenvolver de forma simples , mas não menos profunda no resto da cantiga. Quando um provérbio aparece no fim é para "encerrar" a quadra com uma "lição moral" que se pretende dar. Do ponto de vissta do material proverbial tipicament brasileiro, encontraramse alguns exemplos, embora predominassem provérbios existentes também em Portugal. No que diz respeito à temática proverbial, a mais usada nas cantigas portuguesas e brasileiras é a amorosa, e isso testemunha a importância que se dá ao amor nos dois espaços culturais e imaginários populares.

\section{REFERÊNCIAS BIBLIOGRÁFICAS}

BRAGA, Teóphilo. Cancioneiro Popular Portuguez. Lisboa: J. A Rodrigues \& C Editores, 1914.

CASCUDO, Luís da Câmara. Literatura Oral no Brasil. 3 ed. Belo Horizonte/ São Paulo: Editora Itatiaia/Editora da Universidade de São Paulo, 1984. Reconquista do Brasil (nova série), v. 84.

CASCUDO, Luís da Câmara; ROSSATO, José Carlos. Nosso Folclore. São Paulo: Editora Soma, 1987.

CASCUDO, Luís da Câmara; WAITES, Bernard et. al. Popular Culture, Past and Present. London: Routledge/The Open University Press, 2001. 
CORREIA, João David Pinto. "A literatura popular e as suas marcas na produção literária do século XX - Uma primeira Síntese". Separata da Revista Lusitana, Nova Série, n. 9, Lisboa, 1998.

CORTESÃO, Jaime. Cancioneiro popular, antologia precedida por um estudo crítico. Porto: Renascença Portuguesa, 1914.

GUERREIRO, Manuel Viegas. Para a história da literatura popular portuguesa. Lisboa: Instituto de Cultura Portuguesa, 1978.

MOTA, Leonardo. Adagiário brasileiro. Belo Horizonte/São Paulo: Itatiaia/Editora da Universidade de São Paulo, 1987.

NOGUEIRA, Carlos. O essencial sobre a literatura de cordel portuguesa. Lisboa: Imprensa Nacional/Casa da Moeda, 2004.

NUNES, Maria Arminda Zaluar. O cancioneiro popular em Portugal. Lisboa: Instituto de Cultura Portuguesa, 1978.

ROMERO, Sílvio. Cantos populares do Brasil.Introdução e notas comparativas de Theophilo Braga, v. II. Lisboa: Nova Livraria Internacional de Lisboa, 1893.

SANTOS, Maria Alice Moreira (org.). Dicionário de provérbios, adágios, máximas, aforismos e frases feitas. Porto: Porto Editora, 2000.

VASCONCELLOS, José Leite de. Poesia amorosa do povo português. Lisboa: Viúva Bertrand e Cia./Sucessores Carvalho \& Cia., 1890.

XATARA, Maria Cláudia; SUCCI, Thais Marini. "Revisitando o conceito do provérbio". Veredas revista de estudos linguísticos, Juiz de Fora, n. 1, p. 33-48, 2008.

Anamarija Marinović é licenciada em língua espanhola e literaturas hispânicas pela Faculdade de Filologia da Universidade de Belgrado, mestre em língua e cultura portuguesa (Português Língua Estrangeira/Língua Segunda) pela Faculdade de Letras da Universidade de Lisboa, cujo doutorado frequenta atualmente. É pesquisadora colaboradora do Centro de Literaturas e Culturas Europeias e Lusófonas da Universidade de Lisboa e autora do livro Teófilo Braga e a poesia popular, no prelo. 
